\title{
RISK ANALYSIS IN THE PROCESS OF PREPARING AND CREATING A MUNICIPAL PLAN
}

\author{
Tomáš Pavlenko ${ }^{1}$, Ján Dvorský
}

\begin{abstract}
Risks arise during municipal planning activities, the negative impacts of which can influence the lives of local residents. The importance of municipal planning lies in the proposed material and the coordination and timing of activities influencing the environment, cultural-historical values of an area, territorial development, and creation of landscapes in line with principles of long-term sustainable development. By implementing risk management with an emphasis on objectively selecting and assessing risks in the preparation and creation of a municipal plan, an increase in the safety of the territory as a whole is expected. Municipal planning authorities project specific intentions for an area, while coordinating the public's interest. The results of our qualitative assessment of selected risks identified those that were most significant when creating a municipal plan and which require foremost consideration.
\end{abstract}

JEL Classification Numbers: H12, R14 DOI: http://dx.doi.org/10.12955/cbup.v4.791

Keywords: municipal plan, risk, assessment, QRAC.

\section{Introduction}

Municipal planning requires integration of knowledge from several scientific disciplines. Primarily, municipal planning aims to ensure optimal use of areas and this involves the preparation and application of land-planning documentation. Prepared land-planning documentation reflects requests from all interested subjects of the specific area. The development of an area without thorough development of a municipal plan is deemed impossible, especially in towns and larger municipalities where the processing of a municipal plan is mandated by law. Circumventing a thoroughly prepared municipal plan by choice is difficult, with the effective use of an area impossible. Investment, which is clearly bounded by criteria that only a thoroughly prepared municipal plan can guarantee, is also linked to incorrect use of the territory. Risks arising from the process of creating land-planning documents and the municipal plan itself, with short-sighted decisions, could lead to unsuitable use of properties and buildings incorrectly located in an otherwise attractive area.

Therefore, the process of developing new or existing land-planning documentation or specific municipal plans can lead to many inaccuracies. Errors made in the processing of a municipal plan, an instrument for sustainable development of a territory, can result from many risks arising during this process. From an analysis of land-planning documents, the risks arising during this process are identified in this contribution. The identified risks are subsequently assessed through a qualitative method. Through use of these methods, risks that need to be taken into consideration are presented.

\section{A municipal plan as an instrument for sustainable development of a territory}

The creation of municipal plans, land-planning documents, and other land-planning documentation are defined in Act no. 50/1976 Collation (Coll.) of the Territorial Planning and Building Code (the Building Act), as amended (Building Act, 2014). Land-planning documents are reports and data files prepared for the purpose of municipal planning using municipal planning methods, acquired and negotiated according to the Building Act. These are used in the processing of municipal plan proposals or for ensuring the range of needs in updating municipal plans. They are procured for verification of possible solutions to problems in the territory, strengthening solutions for individual elements of a settlement, or obtaining data and information about a territory. Figure 1 depicts the landplanning documents used in preparing a municipal plan, under the Building Act.

An "Urban Planning Study" resolves the spatial arrangement and functional use of an area, especially of urban land, the architectural and local-technical conditions for using natural resources within a territory, and the overall potential of the territory. A component of an urban planning study is

\footnotetext{
${ }^{1}$ Tomáš Pavlenko, Faculty of Security Engineering, University of Žilina, Slovakia, Tomas.Pavlenko@ fbi.uniza.sk

2 Ján Dvorský, Faculty of Security Engineering, University of Žilina, Slovakia, Jan.Dvorsky@ fbi.uniza.sk
} 
describing the development of the population, the age structure, national composition, and education of the populace (Betáková, Dvorský, Pavlenko, \& Mižičková, 2015).

Figure 1: Land-planning documents in the process of preparing and creating a municipal plan

Source: Authors

A "General Building Scheme" is a document that resolves in detail the problems of individual components of a territory's settlements, especially problems of housing, industry, agriculture and forest management, transport or other public infrastructure, protection of nature and landscapes, recreation, and sport. It is used for expanding knowledge about a certain element of a settlement when either procuring or revising a municipal plan (Betáková et al., 2015).

"Land-planning technical documents" for an area comprise data files detailing the current possibilities for using a designated part of the territory, especially regarding use of natural resources and land potential, the development of individual components of settlements, and resolution of the clash of interests and types of human activities in the area. These documents are used in preparing other landplanning materials with the long-term monitoring of functional areas, including any proposed changes, and the regular assessment of spatial arrangement within an area, including the principles of such organization. At the same time, they are used in monitoring the burdening of the area, the use of natural resources, and the overall potential of the land and placement of new buildings. They are further used for processing orders in developing a concept or update of a municipal plan or determining the need for any plan updates (Betáková et al., 2015).

\section{Identification of risks when processing land-planning documents for preparing and creating a municipal plan}

An analysis of land-planning documents for preparing and creating a municipal plan of Žilina revealed all levels of the system required a large amount of relevant information. Processing land-planning documentation is connected to specific risks that may significantly influence the creation and outcome of a municipal plan (Betáková, Dvorský, \& Havierniková, 2014a). We held mutual meetings and consultations with competent persons responsible for the area of municipal planning in Žilina and who process the above-mentioned documentation, as well as persons responsible from the area of crisis management and civil defense who provide such documents in a form of analyzing the territory. On this basis, we formulated the risks according to Betáková, Lorko, and Dvorský (2014b), as follows:

1. Financial risk - risk connected with insufficient financial resources;

2. Time risk - risk connected with the duration of preparation and procuring of land-planning documentation;

3. Risks arising from lobbying - risk connected with political interconnection of stakeholders and their interest in the functional use of the territory;

4. Administrative risk - risk with the processing of administrative documents;

5. Risk from providing personnel - risk connected with employing qualified personnel; 
6. Legal risk - risk following from legal standards which have an impact on the creation of landplanning documentation; and

7. Information risk - a lack of information necessary with the creation of land-planning documentation.

To identify the risks involved in preparing and creating a municipal plan, methods of logical thinking, such as analysis, synthesis, deduction, and comparison, were applied. In the following section, we analyze the identified risks using a qualitative method of risk analysis, i.e. Qualitative Risk Analysis Correlation (,QRAC”). The main goal was to determine the most significant risks that negatively threaten the process of preparing and creating a municipal plan.

\section{Analysis of risks when processing land-planning documents in preparing and creating a municipal plan using the qualitative QRAC method}

The QRAC method is based on an assumption that risks mutually influence and develop one another. This qualitative method of risk analysis identifies the risks requiring priority in the processing of landplanning documentation. Its assumption means that a specific risk may trigger another risk and the origin of a crisis. This could involve an increasing probability of negative consequences and crisis manifestation (Šoltés \& Štofková, 2015). The risks identified in the previous section were used in a risk correlation. An essential condition in this process was identifying the correlations between the risks to determine relationships among them. The correlations between the risks are presented in Table 1 , where " 1 " indicates a risk that evokes another risk and " 0 " a risk that cannot be evoked another risk (Janásek \& Osvaldová, 2010). The last column and row of the table contains the sums of all risks elicited by each specific risk (Pacinda, 2015).

\begin{tabular}{|c|c|c|c|c|c|c|c|c|}
\hline \multicolumn{8}{|c|}{ Identified Risks } & \multirow{2}{*}{$\sum$} \\
\hline Risks & 1. & 2. & 3. & 4. & 5. & 6. & 7. & \\
\hline 1. & 0 & 0 & 1 & 1 & 1 & 0 & 0 & 3 \\
\hline 2. & 1 & 0 & 1 & 0 & 0 & 0 & 1 & 3 \\
\hline 3. & 1 & 0 & 0 & 0 & 0 & 1 & 0 & 2 \\
\hline 4. & 0 & 0 & 0 & 0 & 0 & 1 & 1 & 2 \\
\hline 5. & 1 & 0 & 1 & 1 & 0 & 0 & 1 & 4 \\
\hline 6. & 0 & 1 & 1 & 0 & 0 & 0 & 1 & 3 \\
\hline 7. & 0 & 0 & 1 & 1 & 1 & 1 & 0 & 4 \\
\hline$\sum$ & 3 & 1 & 5 & 3 & 2 & 3 & 4 & \\
\hline
\end{tabular}

Source: Authors

In the next step, we converted the risk correlations (Table 1) into mathematical and graphical forms. In the mathematical form, the coefficients of activity and passivity of the individual risks were determined. The coefficient of activity, $\mathrm{K}_{\mathrm{ARi}}$, is the percentage of risks that may be elicited by the effect of a risk, $R_{i}$. The coefficient of passivity, $K_{P R i}$, is the percentage of risks that may elicit the effect of a risk, $\mathrm{R}_{\mathrm{i}}$. The percentages relate to the number of risks that can occur (Pacinda, 2015).

For expression of the coefficients, KARi and KPRi, it was necessary to determine the number of combinations where a risk, $\mathrm{Ri}$, could either evoke another risk or be evoked by another. For $\mathrm{x}=$ number of risks, the number of combinations was equal to $x-1$. The relationships for calculating the activity coefficient (Equation 1) and passivity coefficient (Equation 2), according to Pacinda (2005), were:

$$
\mathrm{K}_{\mathrm{ARi}}=\frac{\sum R i}{x-1} \cdot 100, \text { for } \sum 1 \text { in line } \mathrm{i} \quad \text { (Equation 1) }
$$




$$
\mathrm{K}_{\mathrm{PRi}}=\frac{\sum R i}{x-1} \cdot 100, \text { for } \sum 1 \text { in column } \mathrm{j} \quad \text { (Equation 2) }
$$

Each risk, $R_{i}$, was characterized by a pair of coefficients, $K_{A R i}$ and $K_{P R i}$. Table 2 displays the results.

\begin{tabular}{|c|c|c|c|c|c|c|c|}
\hline \multirow{2}{*}{$\begin{array}{c}\text { Activity and } \\
\text { passivity coefficients } \\
\text { of risk }\end{array}$} & \multicolumn{7}{|c|}{ Identified risks } \\
\hline & 1. & 2. & 3. & 4. & 5. & 6. & 7. \\
\hline $\mathrm{K}_{\mathrm{ARi}}(\%)$ & 50.00 & 50.00 & 33.33 & 33.33 & 66.66 & 50.00 & 66.66 \\
\hline $\mathrm{K}_{\mathrm{PRi}}(\%)$ & 50.00 & 16.66 & 83.33 & 50.00 & 33.33 & 50.00 & 66.66 \\
\hline
\end{tabular}

On the basis of the risk activity and passivity coefficients, a graph was prepared of the correlations of individual risks. The significance of a risk was achieved by dividing the graph into quadrants with two axes, $\mathrm{O}_{1}$ and $\mathrm{O}_{2}$. Each quadrant related to the significance of the risk, with the quadrant of primary and secondary containing the most serious, as follows, according to Pacinda (2015):

I. area of primary and secondary dangerous risks;

II. area of secondary dangerous risks;

III. area of primary dangerous risks; and

IV. area of relative safety.

Axis $\mathrm{O}_{1}$ runs perpendicular to the $x$ axis and axis $\mathrm{O}_{2}$ to the $y$ axis. The values where the axes $\mathrm{O}_{1}$ and $\mathrm{O}_{2}$ dissect the $x$ and $y$ axes were calculated according to the following (Equation $3 \& 4$ ), based on Pacinda (2015):

$$
\begin{aligned}
& \mathrm{O}_{1}=\mathrm{K}_{\mathrm{A} \max }-\frac{\left(K_{A \max }-K_{A \min }\right)}{100} * 80, \text { for coverage of } 80 \% \text { of all risks } \\
& \mathrm{O}_{2}=\mathrm{K}_{\mathrm{P} \max }-\frac{\left(K_{P \max }-K_{P \min }\right)}{100} * 80, \text { for coverage of } 80 \% \text { of all risks }
\end{aligned}
$$

According to procedures (Pacinda, 2015), coverage of $80 \%$ of all risks is recommended, and with this approach we found $80 \%$ of analyzed risks fell into Quadrant I, primary and secondary dangerous risks.

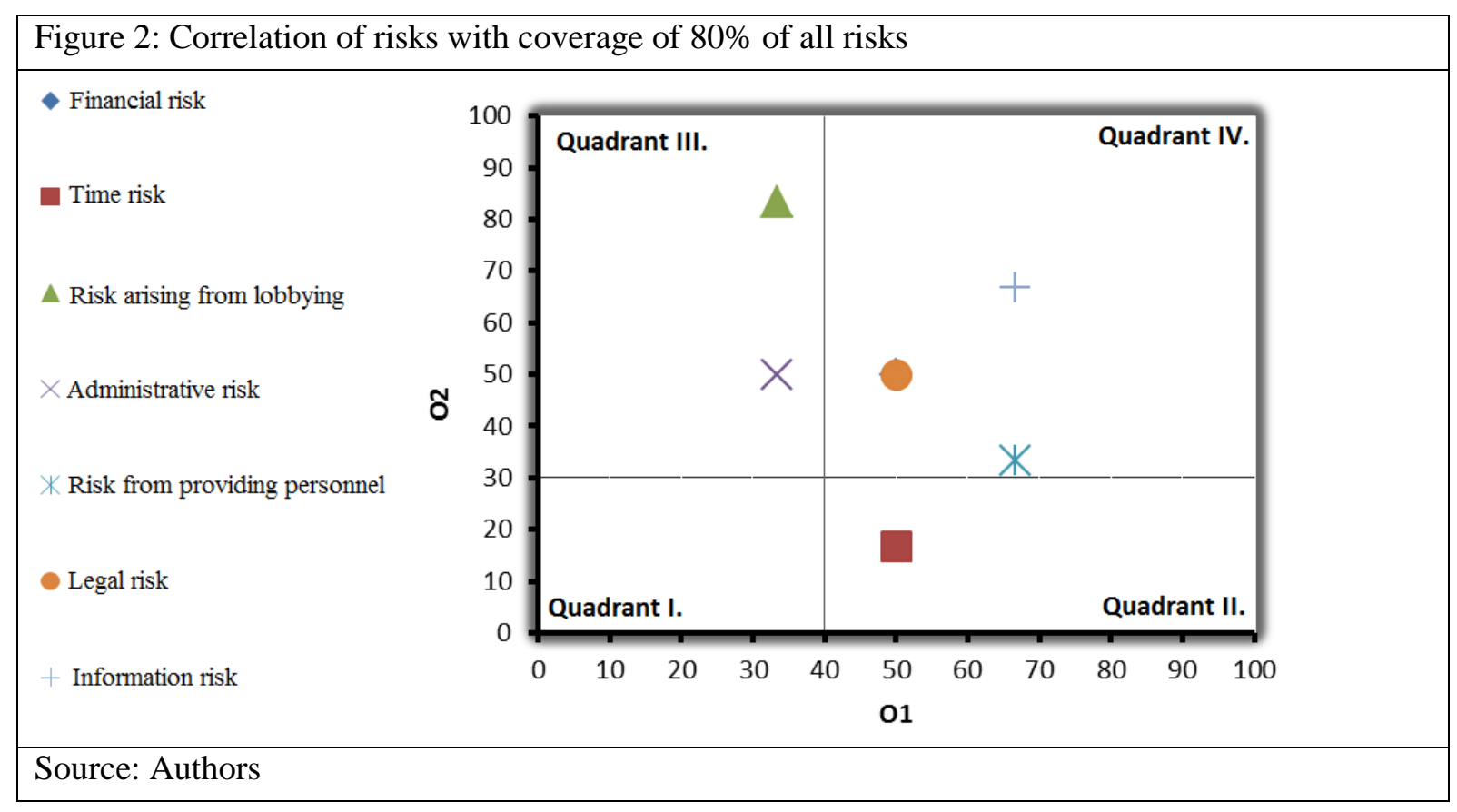


From Figure 2, it is obvious that four risks are located in the quadrant of primary and secondary risks. For this reason, it was necessary to approach the coverage of $30 \%$ of all risks, which is illustrated in Figure 3. The graph of risk correlations with coverage of $30 \%$ of all risks, indicates the largest risk arises with creating the information for the land-planning documentation. A lack of objective information may cause incorrectly processed land-planning documentation, which are essential documents when preparing a municipal plan.

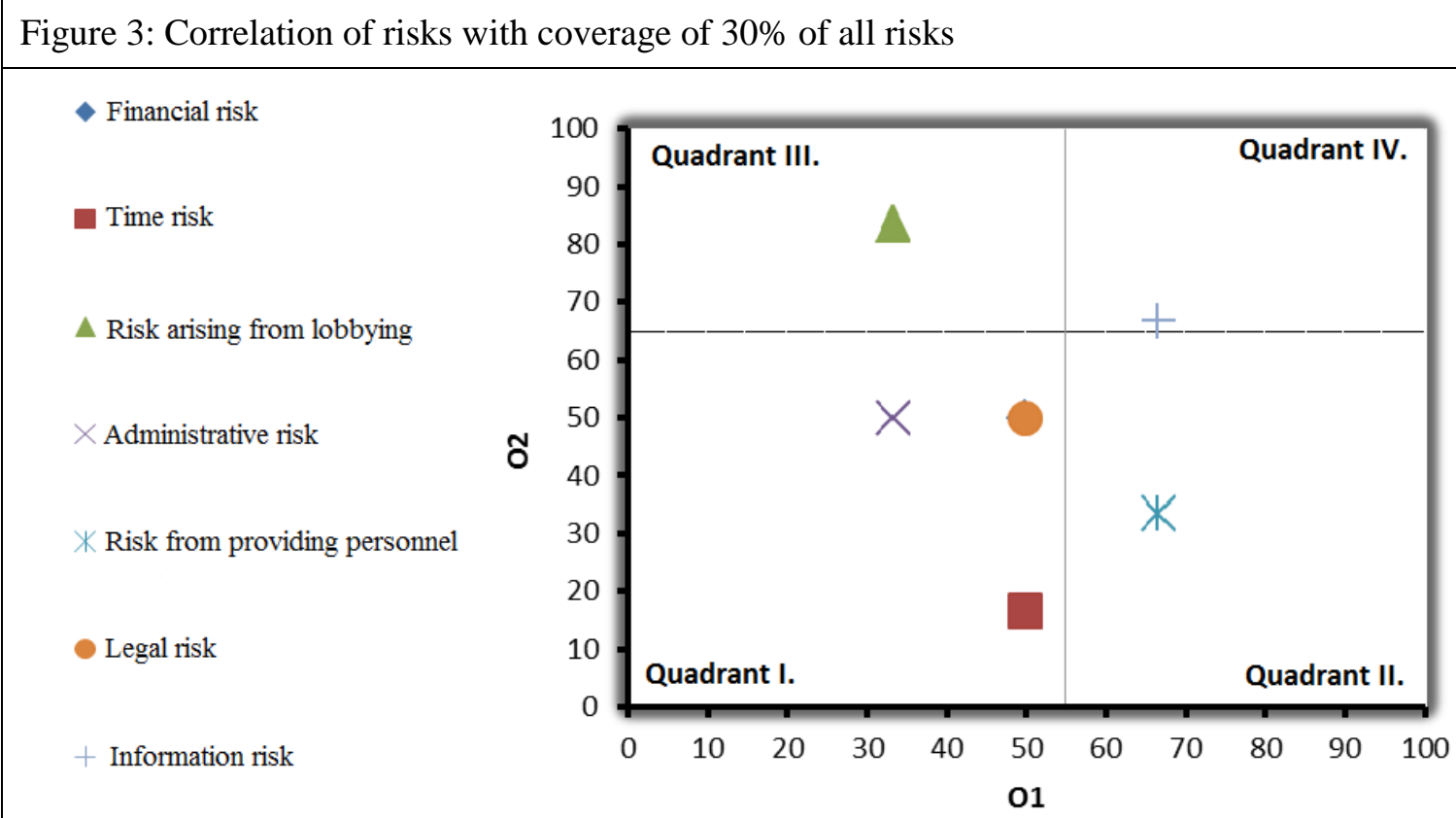

Source: Authors

\section{Conclusion}

Study data were obtained from an analysis of land-planning documents, essential for processing municipal plans, and consultations with experts. This data comprised risks occurring during the processing of the aforementioned documents. The results in this submitted contribution were achieved through use of the QRAC method. This method established the risks that require foremost consideration and which can be resolved with allocation of time. Establishing the most significant risk in the creation of land-planning documentation was possible only by separating the risks, based on $30 \%$ coverage of all risks, as shown graphically. The resulting risk, which would require minimizing, was that of information. Such a risk in the processing of land-planning documents may arise in two ways: 1) unintentionally with incorrect provision and processing of data, and 2) intentionally with provision of inexact and distorted information.

\section{Acknowledgment}

This paper was undertaken as part of the research project IGP201508.

\section{References}

Building Act (2014). No. 50/1976. About territorial planning and building regulations. [online]. [cit. 15.12. 2015]. Retrieved from www.zbierka.sk/sk/predpisy/293-2014-z-z.p-35865.pdf

Betáková, J., Dvorský J., Pavlenko, T. \& Mižičková, L’. (2015). Selected aspects of the spatial impacts of sectoral integration of safety management of environmental risks. Released: Dubnica Institute of Technology, 1. edition. Dubnica nad Váhom, 2015, 106s. ISBN 978-80-89732-65-4.

Betáková, J., Dvorský, J. \& Havierniková, K. (2014a). Social capital and safety perception as aspect of improving regional competitiveness of territory. $2^{\text {nd }}$ International Conference on Management Innovation and Business Innovation, Bangkok, 2014. 68-73 s. ISBN 978-981-09-1685-5. DOI: 10.5729/1nms.vol44.68

Betáková, J., Lorko, M. \& Dvorský, J. (2014b). The impact of the potential risks of the implementation of instruments for environmental area management on the development of urban settlement. Environmental Impact II, Ancona, Italy, 2014. 91101 s. ISBN 978-184564762-9, ISSN 1743-3541. DOI: 10.2495/EID140081 
Janásek, D. \& Osvaldová, L. (2010). Sorption of hazardous materials in road transport. In: Mechanika Transport Komunikacii = Mechanics Transport Communications. ISSN 1312-3823. Broj. 2 (2010), s. UK-9.1-UK-9.8.

Pacinda, Š. (2015). Network analysis and method QRAC, online [cit. 30.11. 2015]. Available on: http://www.populationprotection.eu/attachments/027_vol2n1_pacinda.pdf

Šoltés, V. \& Štofková, K. (2015). Characteristics and development of program budgeting in self-governing region. In: Innovations in science and education: CBU international conference proceedings 2015: March 25-27, 2015, Prague, Czech Republic. Prague: Central Bohemia University, 2015. ISBN 978-80-88042-00-6. S. 50-55. 